\title{
ELECTRICAL AND THERMODYNAMIC PROPERTIES OF A COLLAGEN SOLUTION
}

\author{
Jaromir Stancl ${ }^{a, *}, J_{\text {An Skocilas }}{ }^{a}$, Ales Landfeld $^{b}$, Rudolf $_{\text {Zitny }}{ }^{a}$, \\ Milan Houska ${ }^{b}$ \\ ${ }^{a}$ Czech Technical University in Prague, Faculty of Mechanical Engineering, Department of Process Engineering, \\ Technicka 4, Prague, Czech Republic \\ ${ }^{b}$ Food Research Institute Prague, Radiova 7, Prague, Czech Republic \\ * corresponding author: jaromir.stancl@fs.cvut.cz
}

\begin{abstract}
This paper focuses on measurements of the electrical properties, the specific heat capacity and the thermal conductivity of a collagen solution (7.19\% mass fraction of native bovine collagen in water). The results of our experiments show that specific electrical conductivity of collagen solution is strongly dependent on temperature. The transition region of collagen to gelatin has been observed from the measured temperature dependence of specific electrical conductivity, and has been confirmed by specific heat capacity measurements by a differential scanning calorimetry.
\end{abstract}

KEYWORDS: electrical conductivity; thermal conductivity; specific heat capacity; collagen matter, gelatin, differential scanning calorimetry.

\section{INTRODUCTION}

Collagen is the most abundant protein in animals [1] and is the main component of the extracellular matrix of animal connective tissue [2, 3]. Collagen-based solutions are used mainly in the food industry for extruding sausage casings [4, or for producing vascular grafts in medical applications [5].

The dependence of specific electrical conductivity on temperature has been studied for a wide range of foods, but to the best of our knowledge, there is only very limited information on natural collagenous materials. The temperature dependence of the specific electrical conductivity (SEC) of various kinds of meat (pork, beef, lamb, turkey and chicken meat) measured by an electrical conductivity probe in the temperature range $5-85^{\circ} \mathrm{C}$ has been presented by Zell et al. 6]. Shirsat et al. 7] studied the electrical conductivity of a pork leg and a pork shoulder, and the dependence of the electrical conductivity of pork meat on the fat content in the meat. With the increasing fat content, the electrical conductivity of the meat decreases. Strong dependence of the electrical conductivity on temperature, its structure and the ion content has also been confirmed for an apricot and peach puree [8], for a pomegranate [9] and for various other kinds of fresh fruits and vegetables 10 .

Measurements of the electrical conductivity of the material may be a suitable alternative to the differential scanning calorimetry (DSC) method for identifying structural changes in food materials, e.g. the gelation of a potato or corn starch suspension [11]. The measurement results showed that the specific electrical conductivity of the starch increases linearly with temperature, outside the section where gelation of the starch suspension occurs.
The aim of the presented paper was to study the relationship between electrical and thermodynamic properties (the dependence of specific electrical conductivity and specific heat capacity on temperature) of a collagen solution. The second aim was the measurement of the thermal conductivity to provide more information about the thermal properties of a collagen solution.

\section{MATERIALS AND METHODS}

\subsection{Tested Material AND SAMPLE PREPARATION}

\subsubsection{TESTED MATERIAL}

The tested material (a collagen solution obtained from a local producer) was a water solution of a bovine collagen (type I) extracted from mechanically pretreated bovine skins with no other chemical additives. The material is a viscoelastic paste that looks like "silly putty". The mass fraction of the dry matter collagen in the tested collagen solution was $7.19 \%$. The material was well homogenized by mixing and was not thermally treated. Laboratory tests of tested material were carried out by using a size exclusion chromatography and a UV detection, three characteristic fractions were identified ( $12 \%$ of light fraction $3 \mathrm{kDa}, 15 \%$ of middle fraction $550 \mathrm{kDa}$ and $19 \%$ of the longest fraction $780 \mathrm{kDa}$ ), see [12. The material was stored in a refrigerator, packed in a plastic bag.

\subsubsection{SAMPLE PREPARATION}

Samples for the specific electrical conductivity measurements were prepared from a homogenized collagen solution. Smaller pieces of the collagen solution were taken out randomly from the collagen solution mass (approx. $30 \mathrm{~kg}$ of total mass of collagen solution). Five 


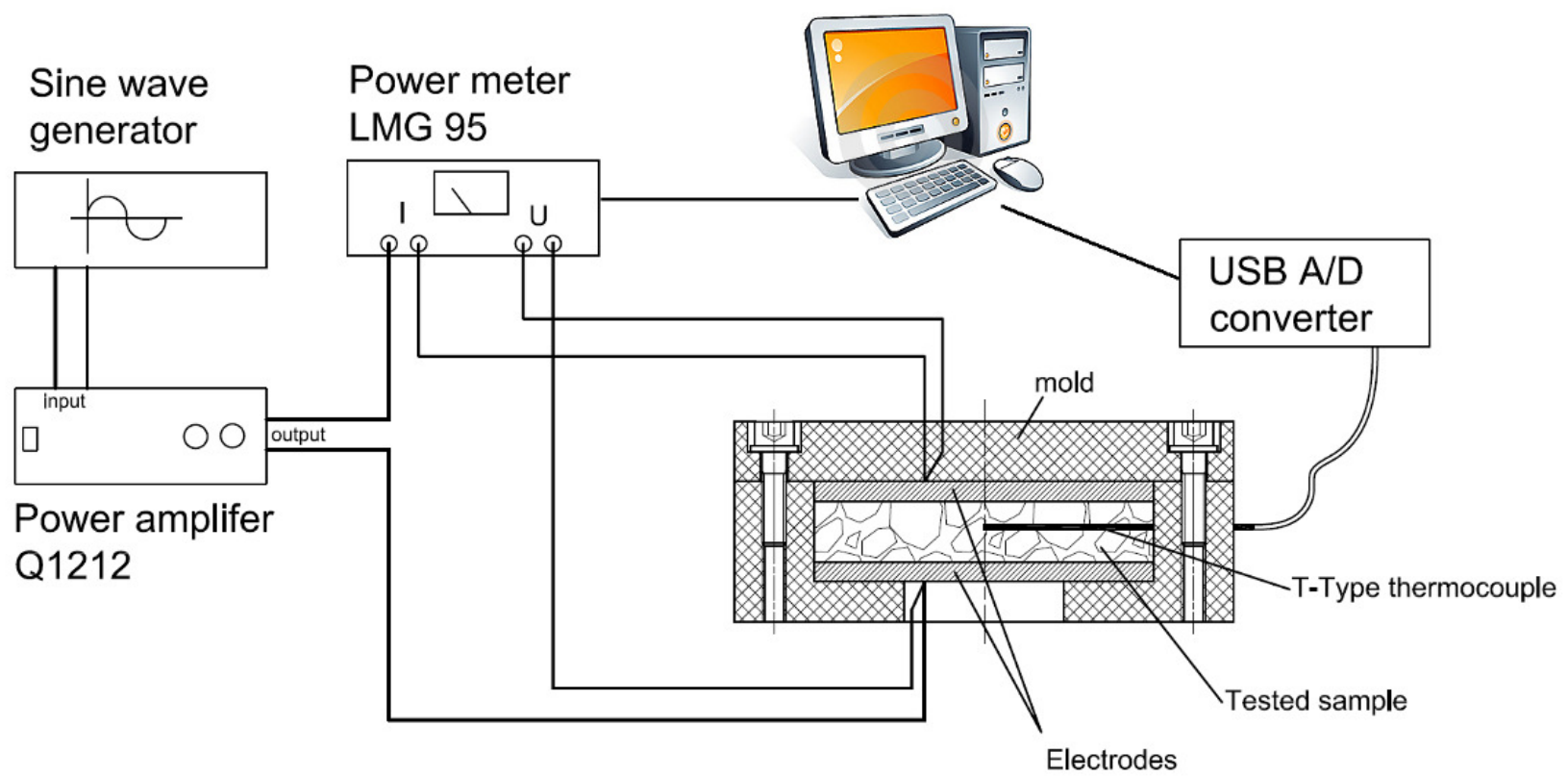

FiguRE 1. Scheme of the experimental setup.

identical cylindrical samples were prepared with the dimensions: diameter $D=85 \mathrm{~mm}$, thickness $h=15 \mathrm{~mm}$. Prepared samples were packed in a plastic bag to prevent desiccation and stored in a refrigerator between measurements.

Samples for the specific heat capacity measurements were prepared from same collagen solution. Five capsules were prepared for the DSC method of the specific heat capacity measurement. The mass of each tested sample (in $40 \mu$ l capsule) was within the range of 15 $25 \mathrm{mg}$.

To perform thermal conductivity measurements, a sample with the dimensions of $150 \times 100 \times 20 \mathrm{~mm}$ was prepared from the mass of the tested collagen material.

\subsection{EXPERIMENTAL SETUP AND PROCEDURE}

\subsubsection{MEASUREMENTS OF SPECIFIC ELECTRICAL CONDUCTIVITY}

A new apparatus was assembled for measuring the specific electrical conductivity of the tested material. A scheme of the experimental apparatus is shown in Figure 1. The apparatus consists of an ohmic cell (a closed plastic mould with a cylindrical gap, where the top and the bottom of the cylindrical gap are formed by planar stainless steel electrodes). The distance between the electrodes was $H=15 \mathrm{~mm}$, and the diameter of the cylindrical gap was $D=85 \mathrm{~mm}$. The electrodes were connected to the power supply. The power supply was assembled from an Electrovoice Q1212 power audio amplifier (Electrovoice, Germany) and a sine wave generator (Wavetek, USA), where it was possible to set the frequency of the electric current. During the experiment, the tested sample was heated by a direct ohmic heating. An LMG 95 electronic power meter (ZES Zimmer, Germany) was used for measuring the voltage $U$ and the electric current $I$. The temperature of the tested material was measured by a T-type thermocouple, which was placed at the geometrical centre of the tested sample. Both electrodes were cleaned using a sand paper and were cooled down before the next measurement. A cylindrical sample of the tested material was placed between two planar stainless steel electrodes, fed by a voltage $U=10 \mathrm{~V}$. The specific electrical conductivity (SEC) was continuously evaluated during an ohmic heating of the sample at approximately constant voltage $U$, recorded together with the electric current $I$ by the power meter. At the same time, the continuous increase in temperature at the centre of the sample was recorded by a T-type thermocouple.

The evaluation of the effective SEC was based on

$$
\kappa=C \frac{U}{I}
$$

with the cell constant $C=H / S$ (where $H$ is the distance between the electrodes, and $S$ is the contact area), as follows from the assumption that the intensity of the electric field $(=U / H)$ inside the heated sample is uniform. Five repeated measurements were performed, a new fresh collagen solution sample was used for each of the measurements.

The SEC of the material can be influenced by the frequency of the electric field. For high electrolyte concentrations, the polarization effects have a negative influence on the electrical conductivity measurements. For low electrolyte concentrations, there is an impact of the capacitances. These negative impacts can be reduced by the right choice of frequency of the electric 


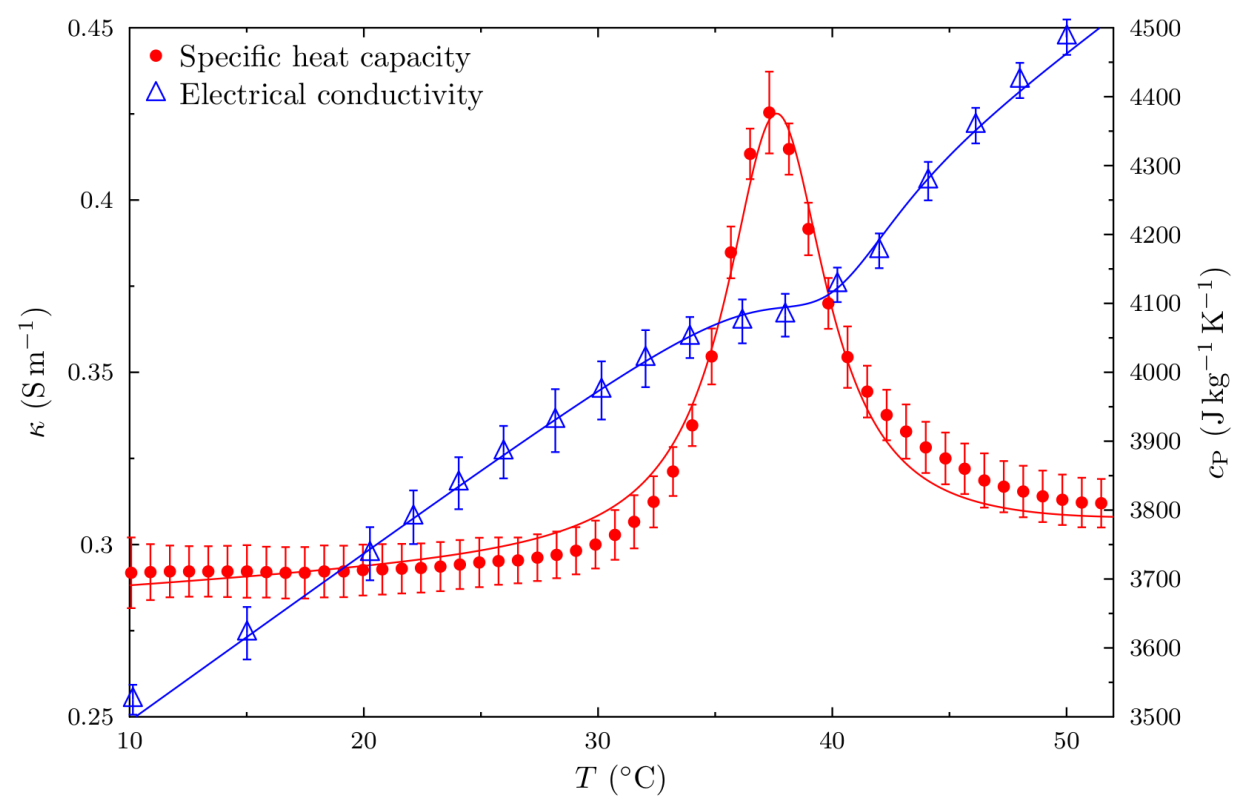

FiguRE 2. The dependence of the specific electrical conductivity (triangles) and the specific heat capacity (dots) on temperature - average from repeated experiments. Model predictions are represented by solid lines.

field used for the SEC measurements. The selection of a high frequency of the electric field reduces the influence of the polarization in highly conductive materials, while the selection of low frequencies reduces the impact of the capacitances in low conductive materials 13 .

Our measurement cell was calibrated using a $0.01 \mathrm{moll}^{-1}$ solution of $\mathrm{KCl}$ with SEC of $0.1413 \mathrm{~S} \mathrm{~m}^{-1}$ (at a temperature of $25^{\circ} \mathrm{C}$ ). The frequency of the electric field of $2.5 \mathrm{kHz}$ was found to be optimal for the tested material, according to the calibration results. The calibration results showed the lowest difference of the cell constant $C$, which was identified by the calibration $\left(C=2.63 \mathrm{~m}^{-1}\right)$, compared to the calculated value according to the geometry of the cell and the assumption of the uniform intensity of the electric field in the tested sample $\left(C=2.64 \mathrm{~m}^{-1}\right)$ at the frequency of $2.5 \mathrm{kHz}$.

\subsubsection{MEASUREMENTS OF THE SPECIFIC HEAT CAPACITY AND THERMAL CONDUCTIVITY}

Measurements of the specific heat capacity of the sample were carried out using a Perkin-Elmer Diamond DSC differential scanning calorimeter with a heating rate of $10^{\circ} \mathrm{C} / \mathrm{min}$. Five repeated measurements were performed, a new fresh collagen solution sample was used for each of the measurements.

The thermal conductivity of the tested material was assessed by a Kemtherm QTM-D3 (Kyoto Electronics, Japan) thermal conductivity meter working on the hot wire (transient) principle. The experiment was repeated ten times with same collagen sample under the condition of a constant ambient and sample temperature of $13^{\circ} \mathrm{C}$. The probe was calibrated using reference plates with a known thermal conductivity before the experiment.

\section{Results OF EXPERIMENTS AND DISCUSSION}

\subsection{SpeCific ElECTRICAL CONDUCTIVITy}

The SEC of the tested collagen material was evaluated from the measured time- courses of the temperature in the geometric centre of the sample and the volt-ampere characteristics in the temperature range from $10-50{ }^{\circ} \mathrm{C}$ for constant frequency of the electric field (frequency of the sine wave) of $2.5 \mathrm{kHz}$ and approximately constant voltage of $10 \mathrm{~V}$. The dependence of the evaluated SEC of the tested material on temperature is shown in Figure 2, The standard deviation of the measured $\mathrm{SEC}$ is $0.008 \mathrm{~S} \mathrm{~m}^{-1}$. Figure 2 shows that the SEC of the tested material depends strongly on temperature. The dependence of the SEC $\kappa$ (in $\mathrm{S} \mathrm{m}^{-1}$ ) of the tested collagen material on temperature in the temperature range from $10-50{ }^{\circ} \mathrm{C}$ can be described by the model in $(2)$.

The parameters of the model for SEC $a, b, c, d$ and $e$ in the following equation were received by a nonlinear regression of the experimental data:

$$
\kappa=a+b T+\frac{c}{1+d(T-e)^{2}} .
$$

Received correlation coefficient $R^{2}=0.999$ confirms that applied model very well represents the experimental data in the temperature range from $10-50{ }^{\circ} \mathrm{C}$. The identified model parameters for the SEC, together with a statistical analysis, are summarized in the Table 1 For all parameters of the SEC model, the temperature is statistically significant parameter, confirmed by a statistical analysis.

Figure 2 also shows a slight decrease in the linear trend of the SEC in the temperature range $32-43^{\circ} \mathrm{C}$, 


\begin{tabular}{cccccc}
\hline Parameter & Unit & Value & $+/-$ & $t$-ratio & Conclusion \\
\hline$a$ & $\mathrm{~S} \mathrm{~m}^{-1}$ & 0.2001 & 0.0034 & 127.4 & significant \\
$b$ & $\mathrm{~S} \mathrm{~m}^{-1}{ }^{\circ} \mathrm{C}^{-1}$ & 0.0049 & 0.0004 & 65.9 & significant \\
$c$ & $\mathrm{~S} \mathrm{~m}^{-1}$ & -0.0228 & 0.0044 & -13.8 & significant \\
$d$ & ${ }^{\circ} \mathrm{C}^{-2}$ & 0.07735 & 0.0275 & 3.4 & significant \\
$e$ & ${ }^{\circ} \mathrm{C}$ & 40 & 0.5926 & 145.8 & significant \\
\hline$R^{2}$ & & 0.999 & & & \\
\hline
\end{tabular}

TABLE 1. The identified model paramaters for SEC and results of statistical analysis for $95 \%$ confidence interval.

\begin{tabular}{cccccc}
\hline Parameter & Unit & Value & $+/-$ & $t$-ratio & Conclusion \\
\hline$a$ & $\mathrm{~J} \mathrm{~kg}^{-1}{ }^{\circ} \mathrm{C}^{-1}$ & 3665.1 & 6.7885 & 1062.7 & significant \\
$b$ & $\mathrm{~J} \mathrm{~kg}^{-1}{ }^{\circ} \mathrm{C}^{-2}$ & 2.0179 & 0.1105 & 35.9 & significant \\
$c$ & $\mathrm{~J} \mathrm{~kg}^{-1}{ }^{\circ} \mathrm{C}^{-1}$ & 634.57 & 14.9065 & 83.8 & significant \\
$d$ & ${ }^{\circ} \mathrm{C}^{-2}$ & 0.14712 & 0.0120 & 25.9 & significant \\
$e$ & ${ }^{\circ} \mathrm{C}$ & 37.614 & 0.0612 & 1210.3 & significant \\
\hline$R^{2}$ & & 0.975 & & \\
\hline
\end{tabular}

TABLE 2. The identified model paramaters for specific heat capacity and results of statistical analysis for $95 \%$ confidence interval.

\begin{tabular}{lccccc}
\hline \multirow{2}{*}{ Method } & \multicolumn{3}{c}{ Start of the gelatin transition } & \multicolumn{2}{c}{ End of the gelatin transition } \\
& $T_{\text {start }}$ & $s$ & $T_{\text {end }}$ & $s$ \\
\hline DSC & 33.7 & 0.39 & 43.4 & 1.15 \\
SEC measurement & 32.8 & 0.79 & 42.5 & 0.95 \\
\hline
\end{tabular}

TABLE 3. A comparison of the identified temperature region of the collagen transition to gelatin from the DSC measurements and the SEC measurements. $T_{\text {start }}$ corresponds to the start of the peak observed from the DSC measurements and the sudden slope change from the SEC measurements; $T_{\text {end }}$ corresponds to the end of the peak observed from the DSC measurements and the slope change from the SEC measurements. The presented temperatures values are the average value from repeated experiments; s indicates the standard deviation of the temperatures.

where natural collagen denatures and changes its structure into gelatin. A peak in the temperature dependence of the specific heat capacity of the tested collagen by the DSC measurements was observed in this temperature range.

\subsection{SPECIFIC HEAT CAPACITY \\ AND THE MELTING REGION \\ OF THE COLLAGEN MATERIAL}

The specific heat capacity of the tested collagenous material was measured by a differential scanning calorimetry (DSC). The temperature dependence of the specific heat capacity is shown in Figure 2. The specific heat capacity of the tested sample increases slightly with rising temperature. The same model as for the SEC (2) was used for predicting the dependence of the specific heat capacity $c_{p}$ (in $\mathrm{J} \mathrm{kg}^{-1}{ }^{\circ} \mathrm{C}^{-1}$ ) on temperature for the tested natural collagen solution in the temperature range from $10-50{ }^{\circ} \mathrm{C}$. This empirical model is usually used for predicting the heat capacity of pork and beef fat [14]. Table 2 contains results of model parameters $a, b, c, d$ and $e$ ( $T$ is temperature in ${ }^{\circ} \mathrm{C}$ ) for specific heat capacity of the tested collagen solution received by the nonlinear regression of the experimental data by (2) together with the sta- tistical analysis. The received correlation coefficient $R^{2}=0.975$ confirms that the used model represents relatively well the experimental data in the temperature range from $10-50^{\circ} \mathrm{C}$. For all model parameters of the specific heat capacity, the statistical analysis confirms that the temperature is a statistically significant parameter.

A peak in the specific heat capacity trend was observed during the experiment. The peak corresponds to the temperature region in which a natural collagen sample denatures and changes its form into gelatin. Table 3 presents the identified temperatures of the probable start and end of the gelatin transition process from the observed peak by the DSC measurements and by the SEC measurements (from the change in the slope). The observed temperatures of the region where the collagen changes into gelatin are almost identical.

Our results show that the denaturation temperature region can also be assessed by electrical conductivity measurements (from the slope change in the course of specific electrical conductivity), but it may not always be entirely conclusive according to the DSC measurements. Similar conclusions for the starch gelation process are presented in [11. 


\begin{tabular}{lll}
\hline Property & Model parameter and value & Validity / Note \\
\hline Spec. electrical conductivity & $a=0.2001 \mathrm{~S} \mathrm{~m}^{-1}$ & $T$ range $10-50{ }^{\circ} \mathrm{C}$ \\
& $b=0.0049 \mathrm{~S} \mathrm{~m}^{-1}{ }^{\circ} \mathrm{C}^{-1}$ & $R^{2}=0.999$ \\
$c=-0.0228 \mathrm{~S} \mathrm{~m}^{-1}$ & \\
& $d=0.07735{ }^{\circ} \mathrm{C}^{-2}$ & \\
& $e=40{ }^{\circ} \mathrm{C}$ & $T$ range $10-50{ }^{\circ} \mathrm{C}$ \\
\hline Spec. heat capacity & $a=3665.1 \mathrm{~J} \mathrm{~kg}^{-1}{ }^{\circ} \mathrm{C}^{-1}$ & $R^{2}=0.975$ \\
& $b=2.0179 \mathrm{~J} \mathrm{~kg}^{-1}{ }^{\circ} \mathrm{C}^{-2}$ & \\
& $c=634.57 \mathrm{~J} \mathrm{~kg}^{-1}{ }^{\circ} \mathrm{C}^{-1}$ & \\
& $d=0.14712^{\circ} \mathrm{C}^{-2}$ & \\
\hline Thermal conductivity & $e=37.614{ }^{\circ} \mathrm{C}$ & $T=13^{\circ} \mathrm{C}$ \\
\hline range of transition into gelatine & $T=33.7-43.4{ }^{\circ} \mathrm{C}$ & $s=0.073 \mathrm{~W} \mathrm{~m}{ }^{-1}{ }^{\circ} \mathrm{C}^{-1}$ \\
\hline
\end{tabular}

TABLE 4. Summarized parameters of the model for predicting $\kappa$ and $c_{p}(2)$ and the physical properties of the tested collagen solution.

\subsection{Thermal CONDUCTIVITY OF COLLAGEN MATERIAL}

Thermal conductivity measurements of the tested collagen solution were carried out to complete the information on basic thermo-physical properties for the tested material. The measurements were performed for a constant temperature of the material of $13^{\circ} \mathrm{C}$. The observed average value of the thermal conductivity of the tested collagen solution from an experiment repeated ten times was $\lambda=0.642 \mathrm{~W} \mathrm{~m}^{-1}{ }^{\circ} \mathrm{C}^{-1}$, with a standard deviation of $s=0.073 \mathrm{~W} \mathrm{~m}^{-1}{ }^{\circ} \mathrm{C}^{-1}$. It is apparent that the thermal conductivity is greatly influenced by the high water content in the tested material.

\section{Conclusions}

Our research has focused on an experimental investigation of the temperature dependence of the SEC and the specific heat capacity of a collagenous material (a solution of bovine skin collagen and water) in the temperature range from $10-50^{\circ} \mathrm{C}$. The thermal conductivity of the tested collagen solution was measured to complete the knowledge of physical properties of this material.

Strong temperature dependence of the SEC of the tested collagen matter was observed. The SEC increases practically linearly with increasing temperature of the tested sample, which is consistent with the Debye-Hückel theory of ionic solutions [15]. Only in the temperature region of $32-43^{\circ} \mathrm{C}$, the slope of the linear course of the electrical conductivity changes, due to the irreversible transition into gelatin. This region was also confirmed by the DSC measurement, where a peak in the temperature dependence of the specific heat capacity was observed. A model has been developed for predicting the temperature-dependent SEC and the specific heat capacity, taking into account the transition of natural collagen into gelatin, and its parameters have been identified. The slope change in the linear course of the SEC is clearly visible, but it may not always be entirely conclusive according to the DSC measurements. However, it can tell us that something has happened in the material.

The thermal conductivity is greatly influenced by the high water content in the tested material. The identified basic information about the physical properties of the tested collagen solution is summarized in Table 4 .

\section{ACKNOWLEDGEMENTS}

This research was supported by the research project GA CR No. 14-23482S (Thermal, electrical and rheological properties of collagen matter).

\section{LIST OF SYMBOLS}

$a, b, c, d, e$ Parameters of the model for $\kappa$ and $c_{p}$

$C$ Constant of the conductivity probe $\left[\mathrm{m}^{-1}\right]$

$c_{p} \quad$ Specific heat capacity $\left[\mathrm{J} \mathrm{kg}^{-1}{ }^{\circ} \mathrm{C}^{-1}\right]$

$D$ Diameter of the electrodes $[\mathrm{m}]$

$f \quad$ Frequency of the electric field $[\mathrm{Hz}]$

$H$ Distance between electrodes [m]

I Electric current $[\mathrm{A}]$

$S$ Contact area $\left[\mathrm{m}^{2}\right]$

$s \quad$ Standard deviation

$T$ Temperature $\left[{ }^{\circ} \mathrm{C}\right]$

$U$ Voltage $[\mathrm{V}]$

GreeK LETTERS

$\kappa$ Specific electrical conductivity (SEC) $\left[\mathrm{S} \mathrm{m}^{-1}\right]$

$\lambda$ Thermal conductivity $\left[\mathrm{W} \mathrm{m}^{-1}{ }^{\circ} \mathrm{C}^{-1}\right]$

SUBSCRIPTS

start Start of irreversible changes in the material end End of irreversible changes in the material 


\section{REFERENCES}

[1] I. J. Haug, K. I. Draget, O. Smidsrod. Physical and rheological properties of fish gelatin compared to mammalian gelatin. Food Hydrocolloids 18(2):203-213, 2004. DOI:10.1016/S0268-005X(03)00065-1.

[2] M. D. Shoulders, R. T. Raines. Collagen structure and stability. Annual Review of Biochemistry 78:929-958, 2009. DOI:10.1146/annurev.biochem.77.032207.120833.

[3] C. Zeltz, J. Orgel, D. Gullberg. Molecular composition and function of integrin-based collagen gluesŮintroducing colinbris. Biochimica et Biophysica Acta 1840(8):2533-2548, 2014. DOI:10.1016/j.bbagen.2013.12.022

[4] J. A. Deiber, M. B. Peirotti, M. L. Ottone. Rheological characterization of edible films made from collagen colloidal particle suspensions. Food Hydrocolloids 25(5):1382-1392, 2011. DOI:10.1016/j.foodhyd.2011.01.002

[5] V. A. Kumar, J. M. Caves, C. A. Haller, et al. Acellular vascular grafts generated from collagen and elastin analogs. Acta Biomaterialia 9(9):8067-8074, 2013. DOI:10.1016/j.actbio.2013.05.024

[6] M. Zell, J. G. Lyng, D. A. Cronin, D. J. Morgan. Ohmic heating of meats: Electrical conductivities of whole meats and processed meat ingredients. Meat Science 83(3):563-570, 2009. DOI:10.1016/j.meatsci.2009.07.005.

[7] N. Shirsat, J. G. Lyng, N. P. Brunton, B. McKenna. Ohmic processing: Electrical conductivities of pork cuts. Meat Science 67(3):507-514, 2004. DOI:10.1016/j.meatsci.2003.12.003.
[8] F. Icier, C. Ilicali. Temperature dependent electrical conductivities of fruit purees during ohmic heating. Food Research International 38:1135-1142, 2005. DOI:10.1016/j.foodres.2005.04.003

[9] H. Darvishi, M. H. Khostaghaza, G. Najafi. Ohmic heating of pomegranate juice: Electrical conductivity and ph change. Journal of the Saudi Society of Agricultural Sciences 12:101-108, 2013. DOI:10.1016/j.jssas.2012.08.003

[10] S. Sarang, S. K. Sastry, L. Knipe. Electrical conductivity of fruits and meats during ohmic heating. Journal of Food Engineering 87(3):351-356, 2008. DOI:10.1016/j.jfoodeng.2007.12.012

[11] F.-D. Li, L.-T. Li, Z. Li, E. Tatsumi. Determination of starch gelatinization temperature by ohmic heating. Journal of Food Engineering 62:113-120, 2004. DOI:10.1016/S0260-8774(03)00199-7

[12] R. Žitný, A. Landfeld, J. Skočilas, et al. Hydraulic characteristic of collagen. Czech Journal of Food Science 33(5):479-485, 2015. DOI:10.17221/62/2015-CJFS

[13] Mettler-Toledo AG, Schwitzerland. A Guide to Conductivity Measurement: Theory and Practice of Conductivity Applications, 2013.

[14] V. P. Latyshev, T. M. Ozerova. Specific heat and enthalpy of molten beef and pork fat (in russian). Kholoilnaja Tekhnika 5:37-39, 1976.

[15] P. Debye. Polar Molecules. New York, USA, Dover Publications, inc., 1929. 